Article

\title{
On Aluminum Honeycomb Impact Attenuator Designs for Formula Student Competitions
}

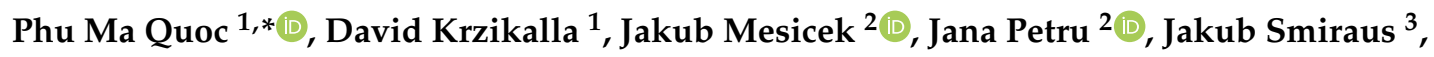 \\ Ales Sliva ${ }^{3}$ (i) and Zdenek Poruba ${ }^{1}$ \\ 1 Department of Applied Mechanics, Faculty of Mechanical Engineering, VSB-Technical University of Ostrava, \\ 70833 Ostrava, Czech Republic; david.krzikalla@vsb.cz (D.K.); zdenek.poruba@vsb.cz (Z.P.) \\ 2 Department of Machining, Assembly and Engineering Metrology, Faculty of Mechanical Engineering, \\ VSB-Technical University of Ostrava, 70833 Ostrava, Czech Republic; jakub.mesicek@vsb.cz (J.M.); \\ jana.petru@vsb.cz (J.P.) \\ 3 Institute of Transport, Faculty of Mechanical Engineering, VSB-Technical University of Ostrava, \\ 70833 Ostrava, Czech Republic; jakub.smiraus@vsb.cz (J.S.); ales.sliva@vsb.cz (A.S.) \\ * Correspondence: phu.ma.quoc@vsb.cz; Tel.: +420-607-326-979
}

Received: 7 September 2020; Accepted: 24 September 2020; Published: 8 October 2020

\begin{abstract}
The use of impact attenuators (IA) is important for vehicles as they absorb the kinetic energy exerted from the car crashes to protect the drivers from any possible injuries. Under the framework of the Formula Student (FS) competition, we investigate various designs of IA made of aluminum honeycomb material. Specifically, the crushing behavior of the honeycomb structure is investigated from the theoretical point of view and later verified with numerical simulations. To achieve the desired crushing behavior of the aluminum honeycomb structure, apart from the so-called pre-crushing method, another way to pre-process the aluminum honeycomb is proposed. Modification on the aluminum honeycomb is done in a symmetric manner to ensure the same uniform crushing behavior on the two sides of the mirror plane of the car. Different variations presented in this paper shed a light on future aluminum honeycomb IA designs in the context of FS competitions.
\end{abstract}

Keywords: formula student; impact attenuator; aluminum honeycomb

\section{Introduction}

Formula Student (FS) is a multinational auto racing competition established to foster university students under the framework of a semi-professional motorsport competition. Joining this competition, students can improve their business and engineering skills while attempting to deliver a racing car to compete with others from different universities [1].

It is possible to construct the vehicle with designed or commercially available components. Among the designable components, there are the bell crank, suspension link, rear upright, etc. [2-5]. The impact attenuator (IA) is as well in this category, and is defined as a deformable, energy-absorbing device mounted forward of the car's front [6]. In practice, porous materials are generally suitable for impact energy absorption due to their internal material structure which allows the progressive collapse under impact loading. Hence, structures such as polymeric foams or aluminum honeycombs are the most favored among FS teams. Due to the ease of access, novice FS teams often purchase the standard, commercially available IA made of foam as shown in Figure 1. The standard IA was also tested in [7]. It was found that the standard IA can be further reduced in size, thus its weight, and still it can meet the competition requirements. 


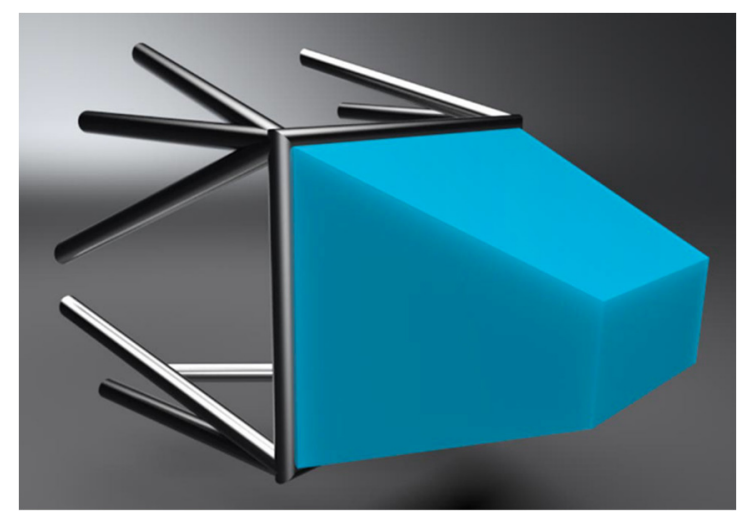

Figure 1. Standard IA [8].

As composite materials become widely available, considerable endeavor is put into the design of composite IA among FS teams and the research community in general. Nevertheless, in 1983 NASA came up with a study of energy-absorbing properties of tubes under compression [9]. Examinations were made for aluminum, glass-epoxy, graphite-epoxy, and aramid-epoxy tubes. Chamfering or notching was suggested to reduce the peak load during the impact. In addition, post-crushing integrity and failure mechanisms were examined. Composite tubes were recently studied for their energy-absorbing properties in [10]. The influence of tube diameter, winding angles, and wall thickness on energy absorption was examined, suggesting that for a larger tube diameter, the absorbed energy is higher. Then, the winding angle of 35 degrees showed more energy absorbed for less compressive strength than other angles. The utilization of composite material (including carbon fibers) was also studied in [11-13]. The papers brought insights about IA design, testing, numerical analysis, and optimization. Optimization methods examined in [11] allowed authors to design an IA with 14\% better energy absorption.

Another group of IA is welded thin-walled structures. Such designs were examined for their impact performance in [14-16]. All designs met FS competition requirements, suggesting another promising method of designing IA. Indeed, this solution is possibly the most feasible and economical in terms of numerical simulation and physical tests.

Owing to the maturity of additive technologies, a lot of studies examined 3D-printed lattice structures of various materials for their energy-absorbing properties. Existing literature suggests that a lot of effort was put into examinations of aluminum alloy lattice structures, made of AlSi10Mg. The authors in [17-19] examined lattice structure designs for energy absorbers manufactured by selective laser melting technology (SLM). The studies provide insights about lattice failure mechanisms, the influence of lattice cell design, and print imperfections on structure performance under impact. The authors in $[17,20]$ found that the heat treatment of AlSi10Mg lattice structure increases its strain capacity suggesting that more energy can be absorbed. Further investigation of lattice cells in $[19,21]$ found that for the same relative density of structure, different types of lattices have different impact resistance. This is caused by different failure modes for different lattice cell designs.

Another favorite material for SLM is alloyed titanium. Lattice structures of titanium alloys were investigated in [22-24]. An interesting combination of materials was investigated in [22]. The authors examined sandwich panels of carbon fiber-reinforced polymer (CFRP) faces which were constructed of two types of core-aluminum honeycomb and titanium alloy (Ti64) lattice structure. It was found that panels with aluminum honeycomb cores have comparable impact resistance as panels with Ti64 lattice structure cores. The disadvantage of panels with Ti64 lattice cores is its double weight compared to panels with aluminum honeycomb. Panels with Ti64 lattice core showed less dent depth and more localized damage area. That is probably caused by the brittle failure mechanism of Ti64 lattices leading to unstable energy-absorbing behavior. Hence, the use of titanium alloy lattices for energy absorbers needs to be further examined. In [23,25], optimum design strategies for Kagome structures were 
investigated. Prediction of the failure of SLM-manufactured lattice structures with a wide range of slenderness ratios and different failure modes was performed. Failure modes and failure locations of Kagome structures were also predicted. Results show that Kagome structures indicated superior performance compared to lattice structures.

Among widely printed materials, there is also stainless steel 316L. The energy-absorbing performance under compression of the SLM-manufactured steel 316L lattice structure was investigated in $[26,27]$. An interesting study was presented in [28], where an SLM-manufactured aluminum lattice structure coated by ceramic was examined for its energy-absorbing properties. A combination of increasing truss angle and oxide coating thickness results in improvements in the compressive strength, energy absorbed per volume and per mass. Improvement in the performance of the structure is caused by the change of failure mode from mid-strut buckling to a hinge kinking mode as the oxide coating thickness increases. In terms of energy absorption, the best performing lattice materials in the study are comparable with the best available cellular materials in the existing literature.

Furthermore, it is worth mentioning the honeycomb structure, which is well known for its remarkably lightweight property, relatively high strength-to-weight ratio and energy-absorbing ability. Honeycomb structures can be metallic (usually aluminum) or nonmetallic (paper reinforced with plastic), with similar unique crushing behavior. The most utilized honeycomb structure is the sandwich shape, as investigated in $[29,30]$, in which the honeycomb layers are glued in between metal sheets to make the airplane walls, vehicle bodies, etc. The aluminum honeycomb block specifically designed for FS competition is available on the website of the Plascore company [31]. Thus, a number of teams purchased the product, tested, and deployed it in their car. As a matter of fact, owing to the complexity of the simulations, a few studies attempted to numerically study the crushing behavior of the honeycomb block in the scope of FS competitions [32-34]. An unusual IA design made from aluminum honeycomb panels and aluminum sheets was examined in [33], which met the competition requirements. For purposes of FS competition, in [34], an aluminum honeycomb IA was examined and compared with a hollow truncated thin-walled pyramid and a hybrid IA made from honeycomb panels bonded to several CFRP plates. It was found that all designs met FS requirements and the hybrid IA was the lightest and the most energy-absorbing. The collapse of aluminum honeycomb structures under compression loading was also examined in [35,36]. The authors in [36] suggested various honeycomb cell shapes which, under out-of-plane compression, performed better than conventional honeycombs. Another interesting design of an energy-absorbing structure utilizing honeycombs was studied in [37]. The authors examined an IA of aluminum honeycomb internally reinforced by corrugated aluminum sheets. Significant enhancement of absorbed energy was found compared to the performance of bare honeycomb or corrugated sheet. As honeycombs are not always loaded purely in-plane or out-of-plane, examination in [38] showed honeycomb performance when inclined cells were compressed, and hence loaded under non-ideal conditions. Results suggested that the angle of inclination dictates the failure mode of cells and that plateau stress is influenced by the inclination angle of cells. The larger cell inclination, the more the plateau stress is reduced leading to less energy to be absorbed. Studies of an innovative approach, aluminum honeycomb reinforced with CFRP tubes in cells, were reported in $[39,40]$. The authors conducted studies of impact behavior of aluminum honeycombs with CFRP tubes in cells. Results showed an increase of about $60 \%$ absorbed energy compared to bare aluminum honeycomb. For designing the IA for FS competition, not only is the absorbed energy the criterion, but there are also average and peak accelerations during the impact. It should be noted that for the majority of the cited studies, the acceleration values were not reported. Hence, suggestions of cited studies should serve future designers as a guide and an encouragement to investigate the real impact properties of their IA design.

For FS vehicles, it is also necessary to design a backing plate for the IA which is called the anti-intrusion plate (AIP). Standard options given by rules are steel or aluminum sheets of specific thicknesses. As the mass reduction of the vehicle is desirable, studies were conducted to see the performance of AIP of different materials. The most frequently investigated material in terms of the 
strength-to-weight ratio is carbon fiber composite. The authors in [41,42] performed examinations of cross-ply unidirectional polyethylene fiber composite under dynamic loading utilizing the bi-material model to evaluate the failure and energy absorption modes. In [43], the thermoplastic composite was evaluated for its penetration resistance-deriving method for the quick design of fiber volume fraction and plate thickness. CFRP plates reinforced by aluminum sheets were tested for their perforation resistance in [44]. Mainly the protection effect of aluminum sheets was investigated. It was found that aluminum sheet helps to distribute the loading from an impact more evenly over CFRP layers contributing to the overall perforation resistance. Regarding the AIP design, suggestions from cited studies can only serve as a guide for the design of AIP for FS vehicles. Further examination of materials and real impact behavior with specific IA used is needed.

Inspired by the above studies, we decide to numerically investigate the crushing behavior of IAs made of aluminum honeycomb. Differing itself from existing works, herein, we simulate the honeycomb block with detailed cell walls in association with a portion of the car's front, as an effort to replicate the real physical crash test that is described in the FS rules. Consequently, our main contributions are as follows:

- We propose an alternative way to process the honeycomb block instead of pre-crushing for energy-absorbing purposes and conducted numerical simulations to verify the concept.

- From the simulation results, we are able to describe the insights of the crushing process which can be useful for future development.

Furthermore, readers can refer to the Figure 2 below for the workflow diagram of this paper:

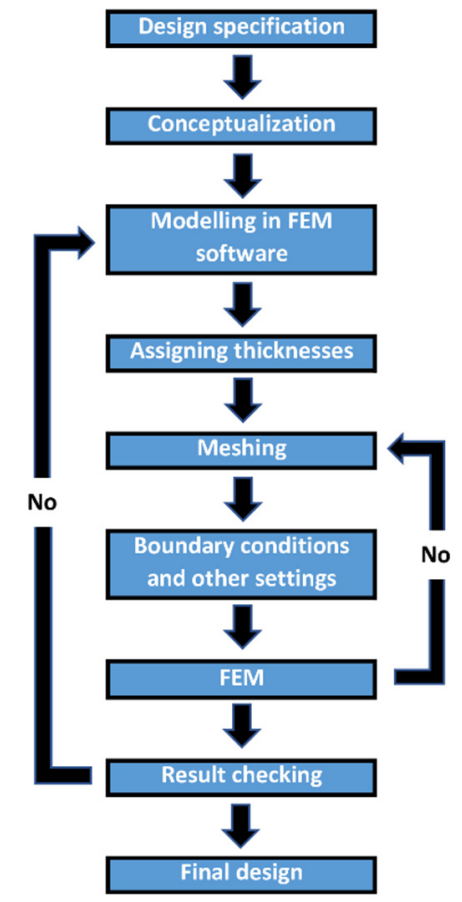

Figure 2. Workflow diagram of the present paper.

\section{Materials and Methods}

In this section, we introduce the honeycomb materials and the typical properties of the aluminum honeycomb making it feasible for shock-absorbing application. The information of the aluminum honeycomb block is taken from real products of the Plascore company and later modeled accordingly for numerical simulations. 


\subsection{Terminologies}

To manufacture the aluminum honeycomb, the corrugated aluminum sheets are joined by means of resistance welding. Inheriting from such a process, the in-between thicknesses (node bonds) are two times the incline walls. It should be noted that for our numerical simulations, we model the node bonds with double thickness according to Figure 3 taken from [45] below. With regard to [46], the single-thickness walls collapse following the same failure mechanism but sooner than the double-thickness walls.

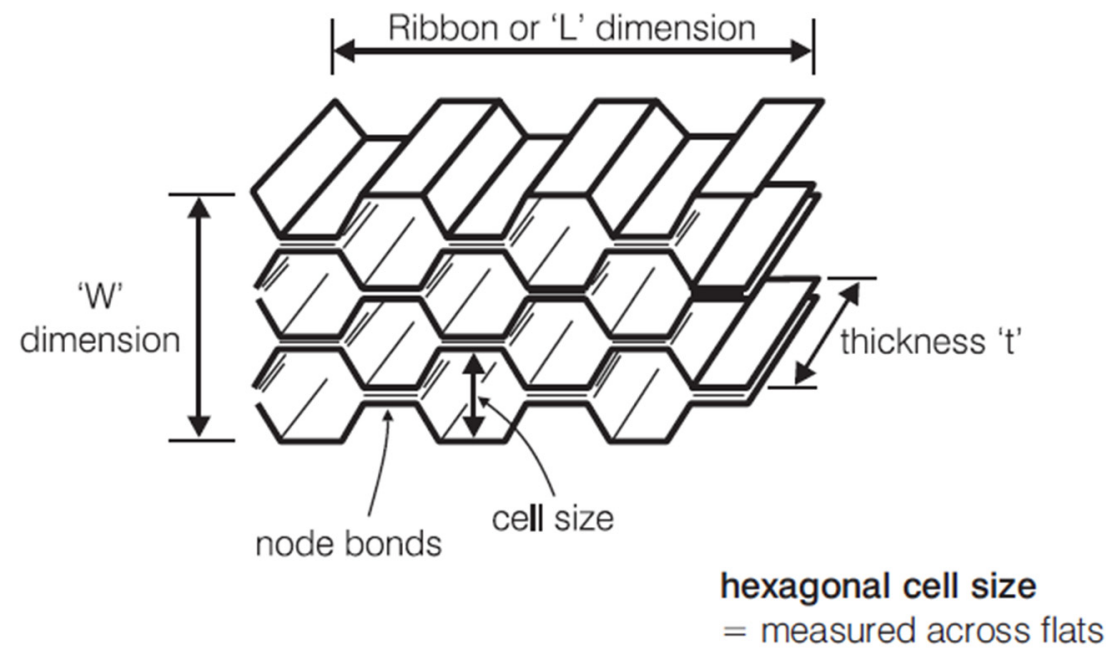

Figure 3. Honeycomb terminologies [45].

For our study, we consider two profiles; namely PAMG-PA3-3.0-38-20-N-5052 (profile A) and PAMG-PA3-5.4-38-40-N-5052 (profile B) in the Plascore's catalog. The naming explains, in order: Aerospace grade aluminum-PA3 corrosion coating-Density-Cell thickness x10,000-Not perforated (N)-Alloy of the material (5052 Al), [47]. It should be noted that only the density and geometric data are employed for modeling the honeycomb cells made with $5052 \mathrm{Al}$. Thus, listed in Table 1 below are our considered details.

Table 1. Honeycomb dimensions.

\begin{tabular}{cccc}
\hline Material & Density & Cell size & Cell Thickness \\
\hline \multirow{2}{*}{ profile A } & $3.0 \mathrm{pcf}$ & $38 \mathrm{inch}$ & 0.002 inch \\
& $\left(0.0480 \mathrm{~g} \cdot \mathrm{cm}^{-3}\right)$ & $(9.525 \mathrm{~mm})$ & $(0.0508 \mathrm{~mm})$ \\
profile B & $5.4 \mathrm{pcf}$ & $38 \mathrm{inch}$ & 0.004 inch \\
& $\left(0.0865 \mathrm{~g} \cdot \mathrm{cm}^{-3}\right)$ & $(9.525 \mathrm{~mm})$ & $(0.1016 \mathrm{~mm})$ \\
\hline
\end{tabular}

Applications of aluminum honeycomb for energy absorption are mostly with impact pressure applied on the out-of-plane surface which is prescribed by $\mathrm{W}$ and $\mathrm{L}$.

\subsection{Properties}

The aluminum honeycomb is orthotropic material. Its applications span widely in aerospace, automobile, marine, and military fields, owing to its lightweight property; excellent energy-absorbing ability; and high strength-to-weight and stiffness-to-weight ratios. Besides, according to [45], it possesses excellent and constant crush strength; high structural integrity; high fatigue, corrosion, and flammability resistance; etc. 


\subsubsection{Crushing Behavior}

For out-of-plane compressive loading, compression applied perpendicularly to the out-of-plane surface, after the structure reaches its ultimate strength, the crushing behavior follows the crush curve as shown in Figure 4 below.

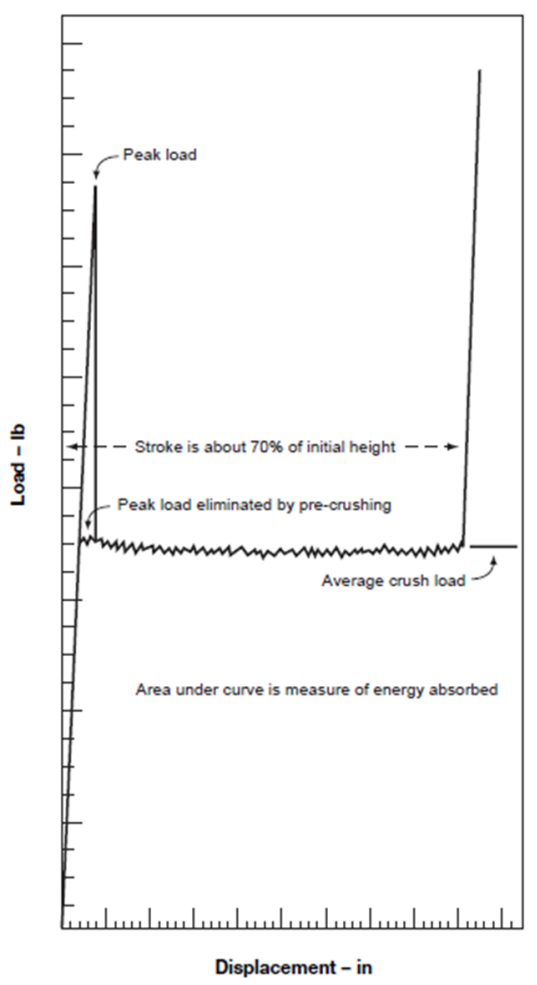

Figure 4. Aluminum honeycomb crush curve [48].

However, the peak load owing to the initialization of the collapse is harmful for under-protected structures [14]. Thus, this peak load is eliminated by a so-called pre-crushing process and what remains is a uniform crush curve.

It should be noted that Figure 4 is taken from the manual of the manufacturer to explain in general the effect of pre-crushing on the crushing behavior of the material. Thus, specific values and units on the axes are not within our interest.

In the next subsection, we discuss the collapse mechanism of the honeycomb cell walls and explain the benefit of the pre-crushing process.

\subsubsection{Collapse Mechanism}

Under out-of-plane compressive loading, at first, the thin-walled cells elastically buckle within the free spaces between the cells, indicated by the rhombus shapes in Figure 5. Further loaded beyond the yield limit, the structure starts to "dimple" (cell walls are hinged among the free space between cells) leading to the plastic collapse of the whole structure [35,46], Figure 6.

This uniform plastic collapse process happens along the thickness of the honeycomb block and corresponds to the flat portion of the curve in Figure 4. During this time, the kinetic energy that the crashing vehicle exerts will be converted uniformly to the deformation energy of the honeycomb block.

The pre-crushing process is able to cut out the peak load because it introduces some initial plastic buckling to the honeycomb block, thus allowing the plastic collapse of the whole structure to happen without the need of initiation from the peak load.

In the next section, we discuss analytical and numerical approaches for computing the IA design. 


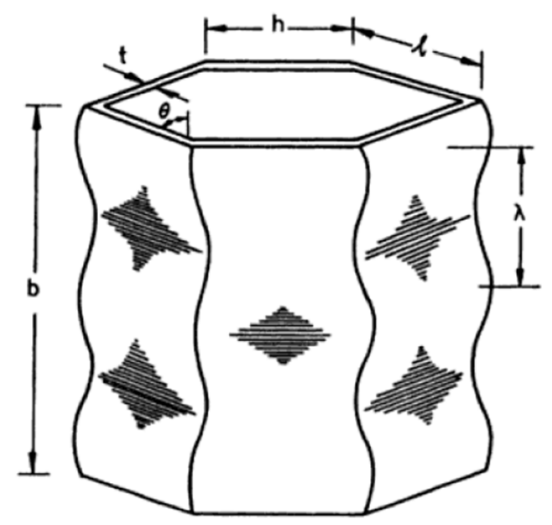

Figure 5. Axial elastic buckling of hexagon cells [46].
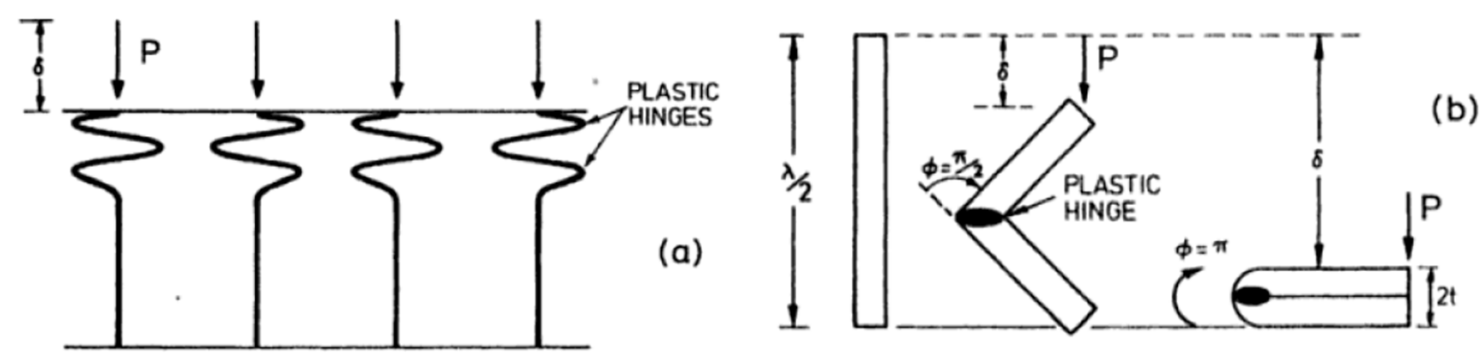

Figure 6. Axial plastic buckling of hexagon cells (a) in general and (b) on one wall, [46].

\subsection{Analytical Estimation of Impact Values}

Given that a car of $\mathrm{m}=300 \mathrm{~kg}$ travels at $\mathrm{v}_{\text {impact }}=7 \mathrm{~m} \cdot \mathrm{s}^{-1}$ to hit a rigid wall. Design an IA that can fully stop the car by absorbing at least $\mathrm{K}_{\mathrm{e}}=7350 \mathrm{~J}$ of the kinetic energy that the car exerts. The decelerations of such event are not higher than $\mathrm{a}_{\text {average }}=20 \mathrm{~g}$ 's on average and $\mathrm{a}_{\text {peak }}=40 \mathrm{~g}$ 's at peak, with $g=9.81 \mathrm{~m} \cdot \mathrm{s}^{-2}$. No part of the AIP deflects more than $25 \mathrm{~mm}$ from its original position.

- Kinetic energy:

$$
K_{e}=\frac{1}{2} m v_{\text {impact }}^{2}=\frac{1}{2} \cdot 300 \cdot(7)^{2}=7350 \mathrm{~J}
$$

- $\quad$ Approximation of impact time:

$$
t_{\text {impact }}=\frac{v_{\text {impact }}}{a_{\text {average }}}=\frac{7}{20 \cdot 9.81}=0.0357 \text {; }
$$

- Deflection of AIP is measured in ANSYS.

There are three versions of IA presented. According to the analytical result, the simulation time was preset to $0.04 \mathrm{~s}$ for the first two versions, and $0.055 \mathrm{~s}$ for the final version. It should be noted that since the simulation time is approximated, we do not know in advance during that period whether the vehicle will be fully stopped or not. This issue is later indicated by the fact that not all the deceleration-time curves converge to zero, as shown later in Section 3.

\subsection{Numerical Solution of Impact Behavior}

We used the ANSYS Workbench for Researcher, Version 18.2 with four processors. In addition, the impact simulations were conducted using the explicit dynamic module. Thus, the below design and setting were conducted following the ANSYS format. 


\subsubsection{Designs for Simulations}

According to the rules [6], in Figure 7, we designed a portion of the car's front for the explicit dynamic simulations. There is an impact attenuator assembly which includes the honeycomb IA, the AIP, and the rectangular front bulkhead (FB). The IA assembly has the plane of symmetry to be $x z O$. From the finite element analysis (FEA) perspective, the model was constructed of shell elements with zero thickness, thus allowing us to flexibly change the thicknesses while saving a considerable amount of modeling and computing time.
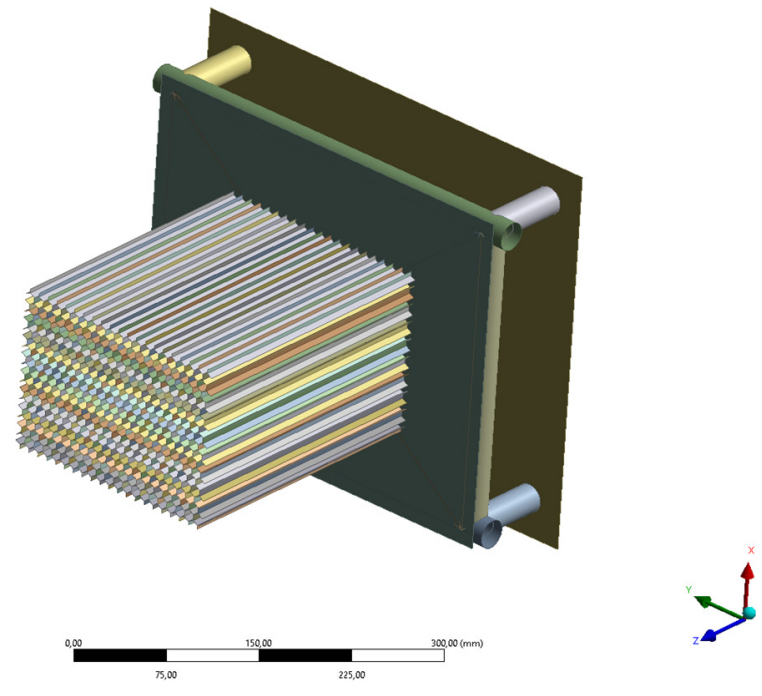

Figure 7. Simulation model, [49].

From left to right, to the $-\mathrm{Oz}$ axis direction, there are:

- Wall: Hidden in Figure 7, which is a rigid plane, normal to the $\mathrm{Oz}$ axis, $1 \mathrm{~mm}$ away from the rear most surface of the IA.

- IA: An aluminum honeycomb block dimensioning $200 \mathrm{~mm} \times 150 \mathrm{~mm} \times 250 \mathrm{~mm}$ (profile A or B), which is further modified for different variations.

- AIP: Rectangular steel plate dimensioning $357 \mathrm{~mm} \times 305 \mathrm{~mm} \times 1.5 \mathrm{~mm}$.

- FB and other tubes: Four round steel tubes forming a rectangle of $307 \mathrm{~mm} \times 255 \mathrm{~mm}$ (center-line distances); one X-bracing or one + -bracing; four extra tubes for mounting the FB on the Vehicle plane. All tubes are round $25 \mathrm{~mm}$, thickness of 2 or $4 \mathrm{~mm}$.

- Vehicle: A rigid plane with an artificial mass of $300 \mathrm{~kg}$.

\subsubsection{Constraints}

The rigid Wall is fixed in space in six degrees of freedom (DOF) at $1 \mathrm{~mm}$ in front of the IA, using Fix Support function. The rest, as a whole, moves at a velocity of $7000 \mathrm{~mm} \cdot \mathrm{s}^{-1}$ in the $+\mathrm{Oz}$ direction to crash into the rigid Wall. Additionally, we use the Bonding joining function to weld the FB and other tubes, the AIP and the FB. The same function is used to glue the IA to the AIP. Last but not least, the separate honey walls are grouped to form a continuous IA block.

\subsubsection{Materials}

Readers can refer to the Tables 2 and 3 below for the Material properties and Material assignment for the simulations.

It is noteworthy that tangent modulus is employed to describe the behavior of materials after being stressed beyond their elastic limits. Values of 1 or $1000 \mathrm{MPa}$ caused no difference to the numerical results as studied by the authors. 
Table 2. Material properties, [49].

\begin{tabular}{ccccc}
\hline & Al $\mathbf{5 0 5 2}$ & Structural Steel (SS) & $\begin{array}{c}\text { Structural Steel } \\
\text { Artificial (SSA) }\end{array}$ & Unit \\
\hline Density & 2680 & 7850 & 214,000 & $\mathrm{~kg} \cdot \mathrm{m}^{-3}$ \\
Young's modulus & 70,300 & 200,000 & 200,000 & $\mathrm{MPa}$ \\
Poisson ratio & 0.33 & 0.3 & 0.3 & - \\
Yield strength & 193 & 200 & 200 & $\mathrm{MPa}$ \\
Tangent modulus & 1 & 1000 & 1000 & $\mathrm{MPa}$ \\
\hline
\end{tabular}

Table 3. Material assignment, [49].

\begin{tabular}{ccccc}
\hline Component & Material & Thickness $[\mathrm{mm}]$ & Type & Note \\
\hline IA & Al 5052 & $\begin{array}{c}9.525 \times 0.1 \text { (profile B) or } \\
9.525 \times 0.05 \text { (profile A) }\end{array}$ & Deformable & $\begin{array}{c}\text { Cell size } \times \text { Cell thickness. } \\
\text { Bond node thickness is } \\
\text { double. }\end{array}$ \\
AIP & SS & 1.5 & Deformable & - \\
FB + other tubes & SS & 2.0 or 4.0 & Deformable & Rigid \\
Wall & SSA & 1.0 & Rigid & 1 mm away from IA \\
Vehicle & SSA & 10 & - \\
\hline
\end{tabular}

\subsubsection{Others}

Simulation results were shown in True Scale, no magnification. Automatic Mass Scaling was turned on (Yes), for the efficient computational time and to avoid the Error of too large Energy. Elements which experienced higher stress level than their yield limit would be eliminated from the IA assembly during the impact. Moreover, it is worth noting that the acceleration was measured in $\mathrm{mm} \cdot \mathrm{s}^{-2}$ then divided by the gravitational acceleration of $\mathrm{g}=9.81 \mathrm{~mm} \cdot \mathrm{s}^{-2}$ to obtain the $\mathrm{g}$ times, providing a perception of weight for the impacts. The deceleration should be on average $20 \mathrm{~g}$ 's and at peak $40 \mathrm{~g}$ 's because these are the limits that a human body can withstand, [50].

\section{Results and Discussions}

In Figure 8, there are simulation results of the three versions modified from the basic shape shown in Figure 7. Besides, the deceleration versus time results during the impact are plotted in Figure 9.

\subsection{Version $1(V .1)$}

According to the rule [6], because of the relative size of the honeycomb block on the AIP, we must consider adding an X-bracing to enhance the stiffness of the FB. We start with a honeycomb block with profile B. Besides, as an attempt to reduce the peak load, we modify the honeycomb block as in Figure 10 below.

It should be noted that the deceleration versus time also indicates the force versus time load. Regarding Figure 9, the vehicle is fully stopped at $0.038 \mathrm{~s}$ and then bounds back. With regard to Figure 7 , the assembly moves in $+\mathrm{Oz}$ direction to crash into the rigid wall. Thus, from 0 to $0.038 \mathrm{~s}$, the acceleration is negative, deceleration. Later on, the positive acceleration indicates the bound back of the assembly. Additionally, the assembly first experiences a peak load at $0.01 \mathrm{~s}$. The peak load is transferred from the honeycomb cells to the AIP and the FB. If the AIP and the FB survive this peak load, the vehicle will continue to be pushed forward and the peak load will initiate the collapse of the honeycomb block. Then, the honeycomb block will attenuate the kinetic energy from the car crash with its deformation energy. 

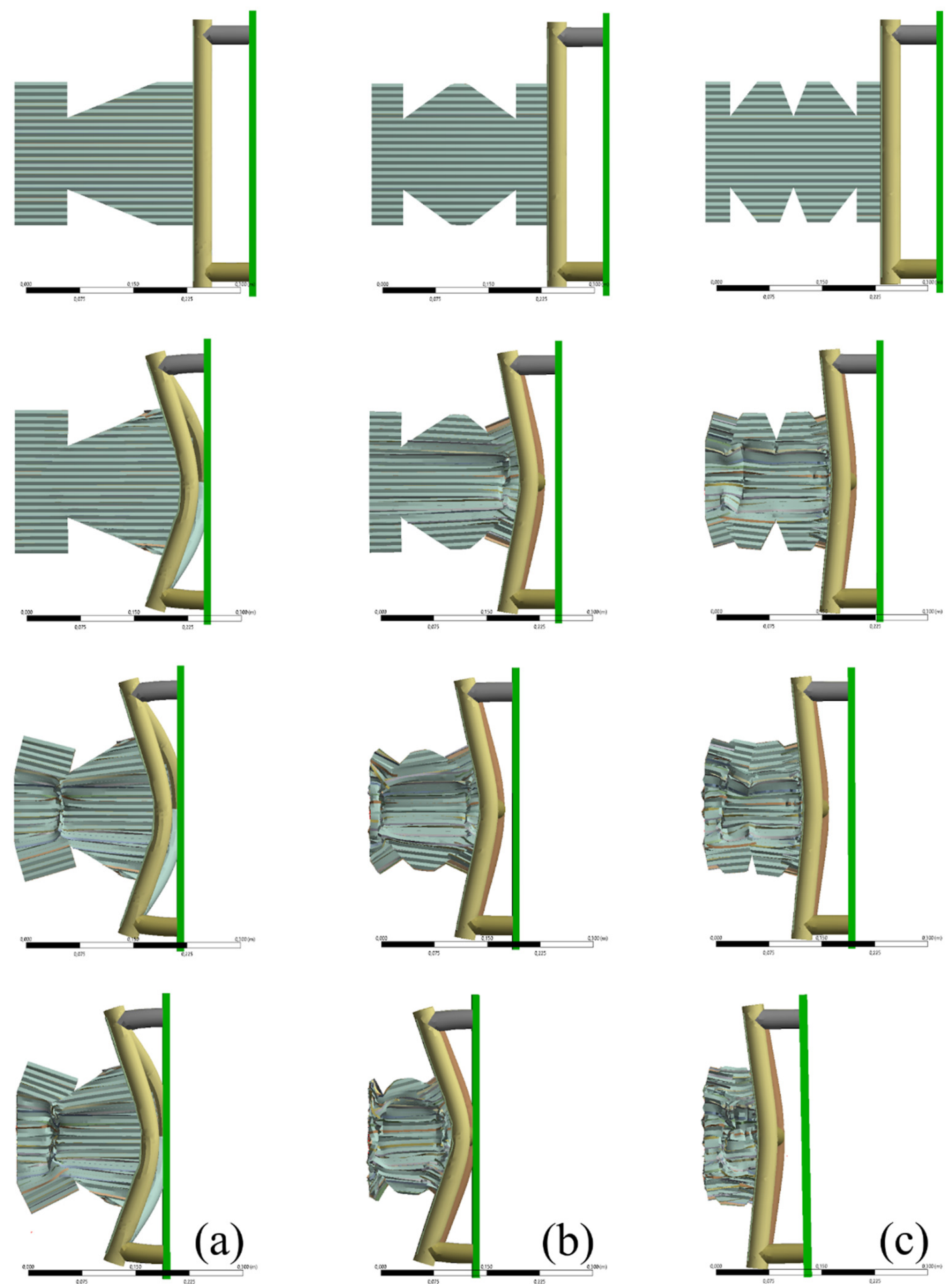

Figure 8. Top view. Three columns from left to right, the deformation shape to time of (a) Version 1 (V.1), (b) Version 2 (V.2), and (c) Version 3 (V.3), respectively [49]. 


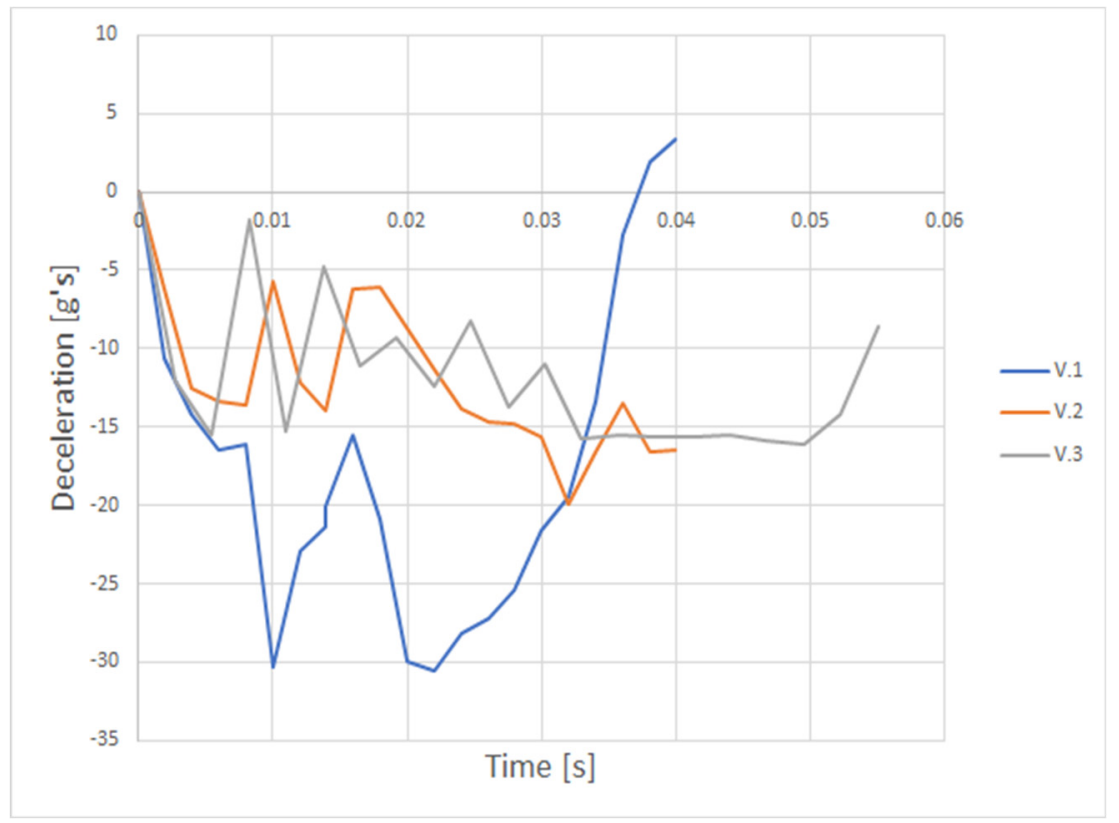

Figure 9. The deceleration versus time curves of V.1, V.2, and V.3, [49].

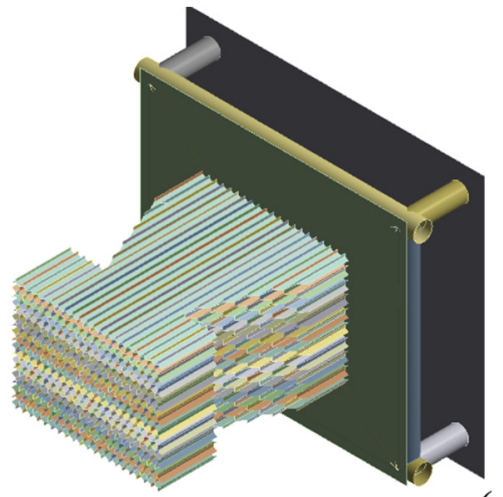

(a)

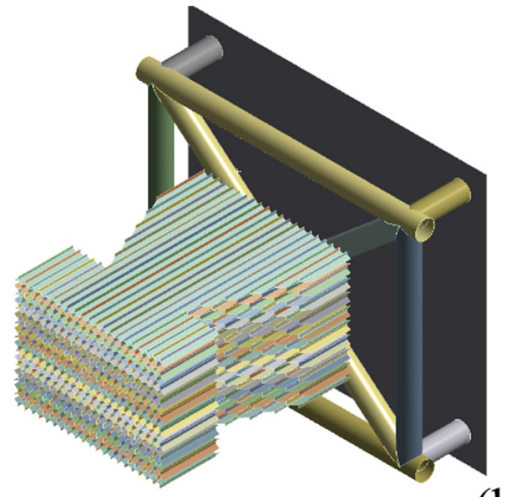

(b)

Figure 10. Design of V.1 (a) with the AIP, and (b) without the AIP, [49].

However, for this version, the AIP and the diagonal tubes of the FB fail under the peak load which is figuratively indicated by the fact that they are squeezed to the rigid vehicle plane at $0.01 \mathrm{~s}$, and henceforth remain intact with the vehicle plane until the end of the simulation.

However, we can notice that the honeycomb block inherits an interesting collapsing pattern. The collapse starts from the shoulder edges which are then folded inward. The kinetic energy is transferred to deformation energy primarily owing to the collapse of the shoulder pattern.

The maximum deformation of the AIP measured from ANSYS as shown in Figure 11 below is $127.1-57.82=69 \mathrm{~mm}$.

We aim to come up with a design which is strong enough to withstand the peak load indicated by the fact that the AIP deflects less than $25 \mathrm{~mm}$. Thus, this version fails.

Subsequently, for the next versions, we investigate further into decreasing the honeycomb block's crashworthiness and increasing the FB's one. 

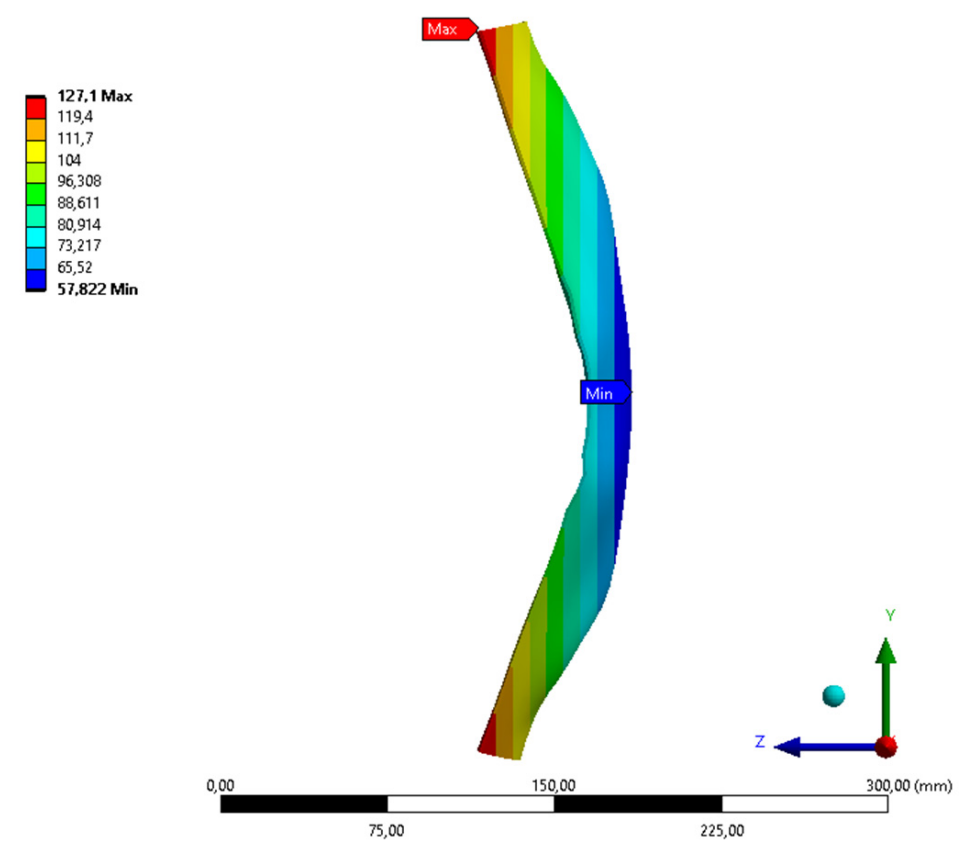

Figure 11. Deformation shape of AIP in V.1, [49].

\subsection{Version $2(V .2)$}

Witnessing that the longer side tubes of the FB experience the most severe deformity, we decide to change the X-bracing to + -bracing to enhance the stiffness of the FB side tubes. In addition, we introduce a so-called double-shoulder pattern on the honeycomb block and change to a smaller honeycomb cell thickness, profile A, to further weaken it as shown in Figure 12 below.

As can be seen in Figure 9, the V.2 curve varies within a smaller range in comparison with V.1. The magnitude of the first peak load, applied within the first $0.008 \mathrm{~s}$ period, is reduced significantly. As a result, the AIP deforms less than V.1. However, it still does not meet the $25 \mathrm{~mm}$ requirement.

The maximum deformation of the AIP measured from ANSYS as shown in Figure 13 below is $185.4-122.5=63 \mathrm{~mm}$.

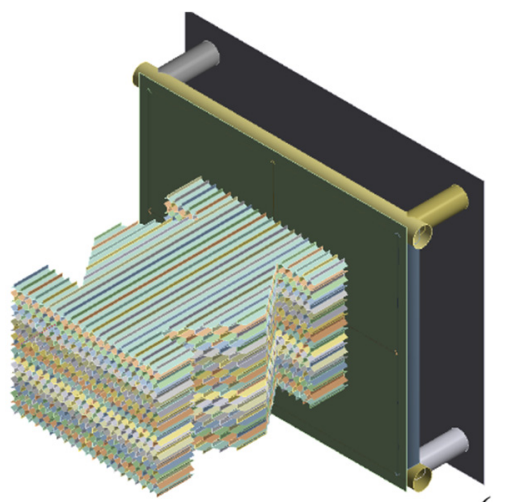

(a)

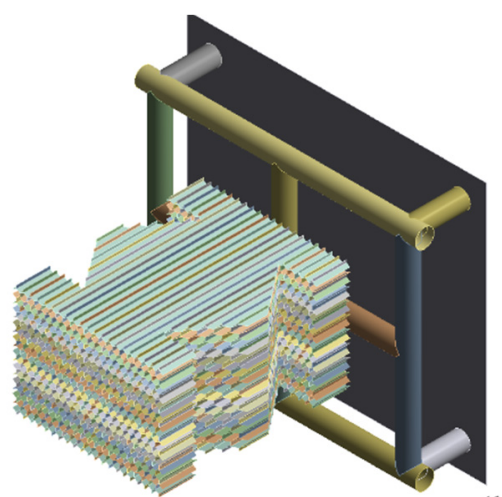

(b)

Figure 12. Design of V.2 (a) with the AIP, and (b) without the AIP, [49]. 

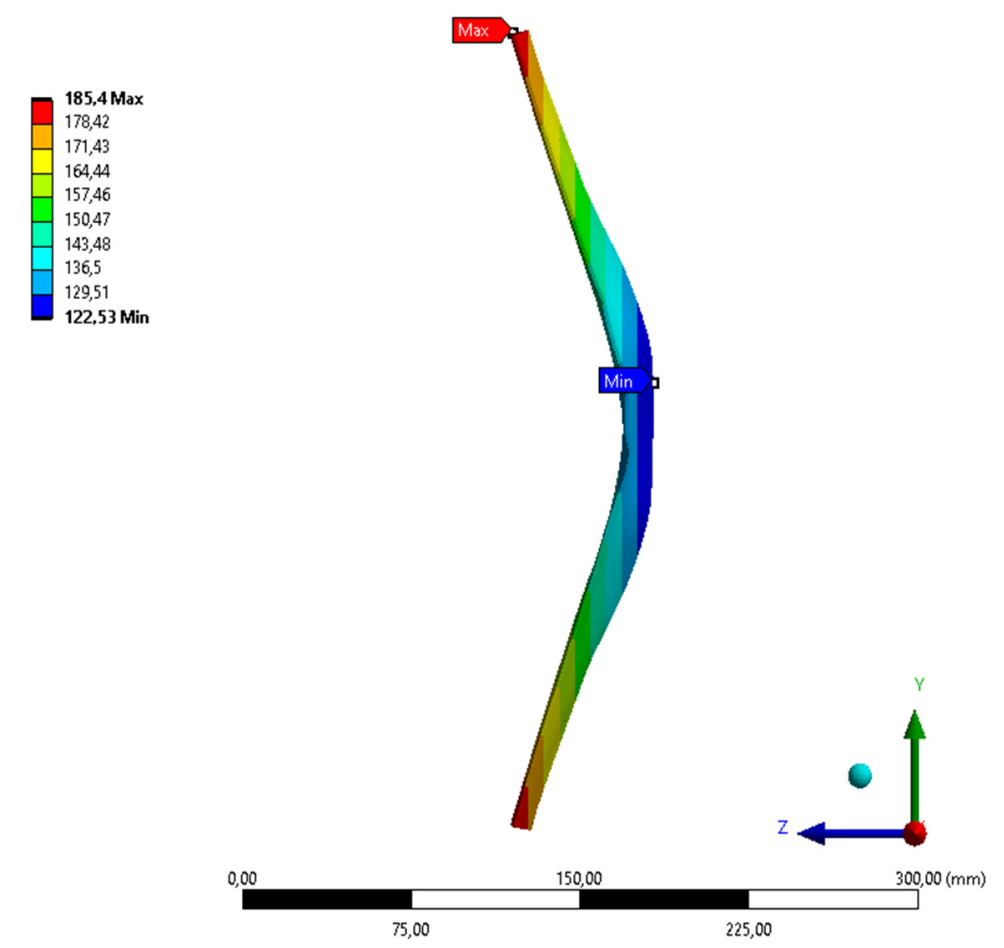

Figure 13. Deformation shape of AIP in V.2, [49].

\subsection{Version 3 (V.3)}

For this version, we further stiffen the FB by increasing the tube thickness of the + -bracing from $2 \mathrm{~mm}$ to $4 \mathrm{~mm}$. Additionally, we further pursue the idea of weakening the profile-A-based honeycomb block with a triple-shoulder pattern as shown in Figure 14 below.

With regard to Figure 8, we can observe that the honeycomb block crashes uniformly. Indeed, this proves the correctness of our findings about the relation between different components contributing to the crashworthiness of the IA assembly. In Figure 9, this uniform crash is indicated by the almost constant trend of the V.3 curve starting from $0.033 \mathrm{~s}$. For vehicle crashes, both in simulations and testing, this constant deceleration is desirable because it helps to ensure the safety of the drivers [10].

The maximum deformation of the AIP measured from ANSYS as shown in Figure 15 below is $195.0-160.6=34.5 \mathrm{~mm}$.
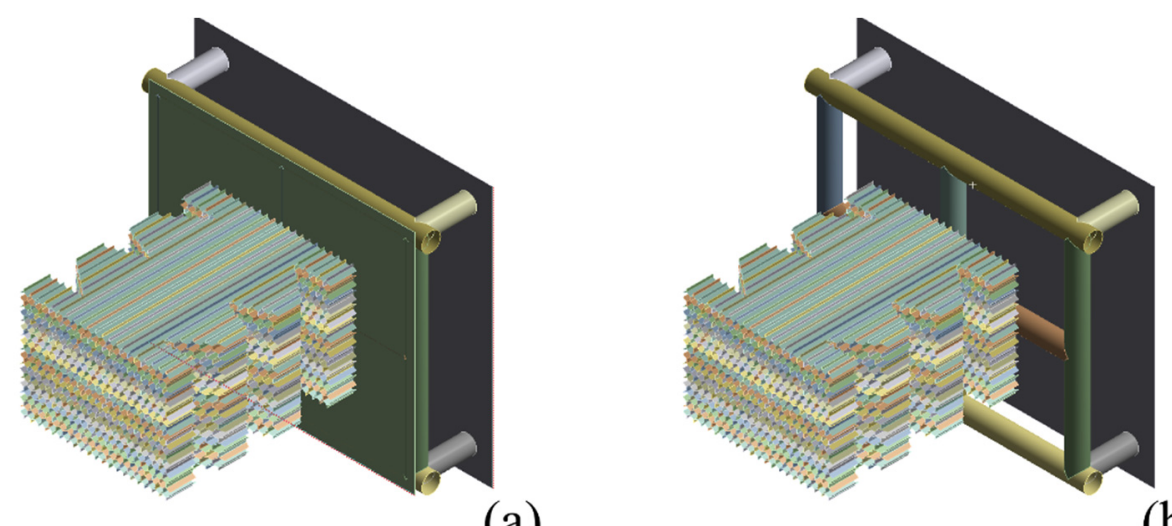

(a)

(b)

Figure 14. Design of V.3 (a) with the AIP, and (b) without the AIP, [49]. 


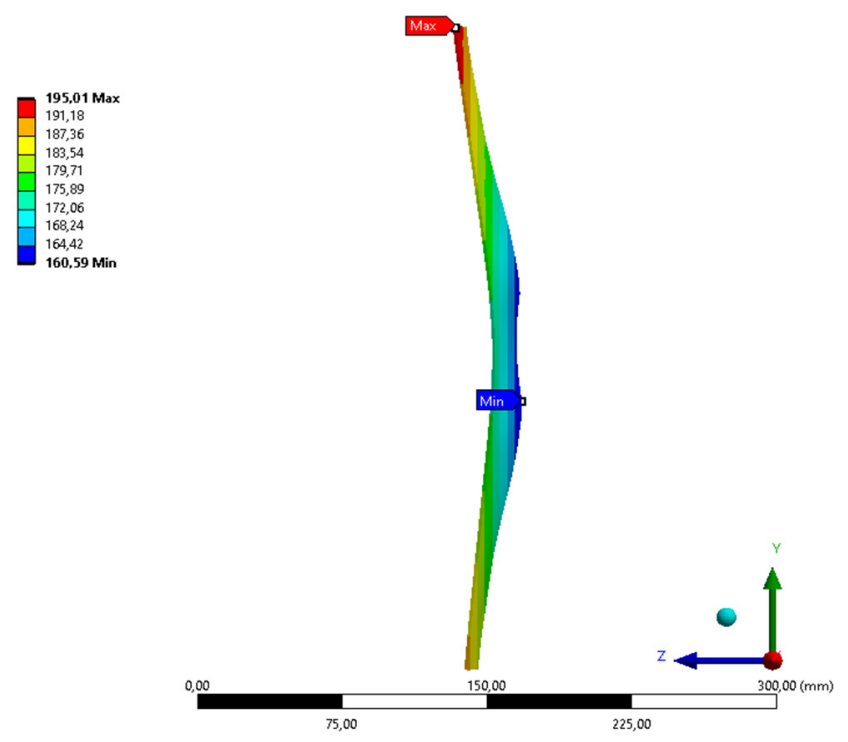

Figure 15. Deformation shape of AIP in V.3, [49].

\subsection{Comparison Studies}

The simulation results are summarized in Table 4 below.

Table 4. Result summary, [49].

\begin{tabular}{ccccc}
\hline Name & $\begin{array}{c}\text { Peak Deceleration } \\
{\left[\mathbf{g}^{\prime} \mathbf{s}\right]}\end{array}$ & $\begin{array}{c}\text { Average } \\
\text { Deceleration [g's] }\end{array}$ & $\begin{array}{c}\text { AIP Deformation } \\
{[\mathbf{m m}]}\end{array}$ & Note \\
\hline V.1 & 30.5 & 18.0 & 69.0 & X-bracing, 2 mm tubes, profile B \\
V.2 & 19.9 & 11.9 & 63.0 & + -bracing, 2 mm tubes, profile A \\
V.3 & 16.1 & 11.8 & 34.5 & + -bracing, 4 mm tubes, profile A \\
\hline
\end{tabular}

Before commenting on the data in the above table, it is worth noting that the deceleration is only calculated for the whole crashing period (until the vehicle stops) in V.1. For V.2 and V.3, we cannot capture the moment the vehicle stops during the preset time.

With reference to Figure 9, within the duration of 0.04 s, we can see that V.1 is fully stopped and even bounds back. The deceleration on average and at peak during this period meets the rules. However, the AIP deformation does not satisfy the rules.

For V.2, at $0.04 \mathrm{~s}$, the deceleration-time curve does not show any trend of rising or declining. The decelerations on average and at peak during this period meet the rules. However, the AIP deformation does not satisfy the rules. This is the worst simulation among the three.

For V.3, at $0.055 \mathrm{~s}$, the deceleration-time curve shows a monotonic trend of rising to zero floor. The decelerations on average and at peak during this period meet the rules. Even though the AIP deformation does not satisfy the rules, we can conclude that this version is the most promising one.

Owing to the time that was permitted for this project, our study stopped at V.3.

\section{Conclusions}

This paper presents crash simulations of aluminum honeycomb IA for the Formula Student VSB-TU Ostrava team. The properties of the aluminum honeycomb are studied from theory and numerical simulations. The effect of different components on the crashworthiness is studied by incrementally developed designs. Specifically, to avoid the force (deceleration) peaks, instead of pre-crushing, we introduce cutting with shoulder pattern. This pattern inherits uniform crushing behavior as shown in the simulation results. Ideally, the force (deceleration) versus time curves are flat. However, in our simulations, the first peak load is reduced but cannot be eliminated thoroughly. The shoulder patterns work well as crush initiators that significantly improve the response of the 
structure from the frontal impact point of view. Possible future works for this would be to re-evaluate the simulation time so that we can capture the moment when the velocity of the vehicle is reduced to zero. Besides, we can evaluate the effect of mesh sizes on the computing time for optimizing the computing resources according to [51]. These two things should be done in the context of better designs according to the findings in this paper.

Author Contributions: Conceptualization, J.S. and J.M.; methodology, Z.P.; formal analysis, P.M.Q. and D.K.; investigation, P.M.Q. and D.K.; writing — original draft preparation: P.M.Q.; writing—review and editing, P.M.Q. and D.K.; supervision, Z.P.; project administration, A.S.; funding acquisition, J.P. All authors have read and agreed to the published version of the manuscript.

Funding: The research was funded in association with project Innovative and additive manufacturing technology - new technological solutions for 3D printing of metals and composite materials, reg. no. CZ.02.1.01/0.0/0.0/17_049/0008407 financed by Structural Funds of the European Union and project.

Acknowledgments: This article has been completed in connection with project Innovative and additive manufacturing technology-new technological solutions for 3D printing of metals and composite materials, reg. no. CZ.02.1.01/0.0/0.0/17_049/0008407 financed by Structural Funds of European Union and project. The authors express their gratitude towards the Formula Student VSB-TU Ostrava for establishing the foundation for this project.

Conflicts of Interest: The authors declare no conflict of interest.

\section{References}

1. Institution of Mechanical Engineers. Available online: https://www.imeche.org/events/formula-student/ about-formula-student (accessed on 19 August 2020).

2. Mesicek, J.; Pagac, M.; Petru, J.; Novak, P.; Hajnys, J.; Kutiova, K. Topological optimization of the formula student bell crank. MM Sci. J. 2019, 2019, 2964-2968. [CrossRef]

3. Kutiová, K.; Měsíček, J.; Krzikalla, D. Experimental examination of adhesive bonded carbon Fibre tube to aluminum alloy AW 7075. Mater. Sci. Forum 2020, 994, 125-132. [CrossRef]

4. Mesicek, J.; Richtar, M.; Petru, J.; Pagac, M.; Kutiova, K. Complex view to racing car upright design and manufacturing. Manuf. Technol. 2018, 18, 449-456. [CrossRef]

5. Hunar, M.; Jancar, L.; Krzikalla, D.; Kaprinay, D.; Srnicek, D. Comprehensive view on racing car upright design and manufacturing. Symmetry 2020, 12, 1020. [CrossRef]

6. Formula Student Rules. 2020. Available online: https://www.formulastudent.de/fileadmin/user_upload/all/ 2020/rules/FS-Rules_2020_V1.0.pdf (accessed on 19 August 2020).

7. Albak, E.I.; Solmaz, E.; Kaya, N.; Öztürk, F. Lightweight foam impact attenuator design for formula Sae car. Turk. J. Eng. 2018, 2, 17-21. [CrossRef]

8. Alexander Bilewski. Available online: https://alexbilewski.myportfolio.com/polsl-racing-2016-impactattenuator (accessed on 19 August 2020).

9. Farley, G.L. Energy absorption of composite materials. J. Compos. Mater. 1983, 17, 267-279. [CrossRef]

10. Muhammad, A. Energy Absorption Behaviour of Filament Wound Glass and Carbon Epoxies Composite Tubes. Master's Thesis, Kano University of Science \& Technology, Wudil, Nigeria, 2014; pp. 30-37. [CrossRef]

11. Boria, S.; Obradovic, J.; Belingardi, G. On design optimization of a composite impact attenuator under dynamic axial crushing. FME Trans. 2017, 45, 435-440. [CrossRef]

12. Boria, S.; Pettinari, S. Mathematical design of electric vehicle impact attenuators: Metallic vs composite material. Compos. Struct. 2014, 115, 51-59. [CrossRef]

13. Wang, J.; Yang, N.; Zhao, J.; Wang, D.; Wang, Y.; Li, K.; He, Z.; Wang, B. Design and experimental verification of composite impact attenuator for racing vehicles. Compos. Struct. 2016, 141, 39-49. [CrossRef]

14. Belingardi, G.; Obradovic, J. Design of the impact attenuator for a formula student racing car: Numerical simulation of the impact crash test. J. Serb. Soc. Comput. Mech. 2010, 4, 52-65.

15. López-Campos, J.; Baldonedo, J.; Suárez, S.; Segade, A.; Casarejos, E.; Fernández, J. Finite element validation of an energy attenuator for the design of a formula student car. Mathematics 2020, 8, 416. [CrossRef]

16. Rooppakhun, S.; Boonporm, P.; Puangcha-Um, W. Design and analysis of impact attenuator for student formula. SAE Tech. Pap. Ser. 2015, 1. [CrossRef] 
17. Maskery, I.; Aboulkhair, N.T.; Aremu, A.; Tuck, C.; Ashcroft, I.; Wildman, R.; Hague, R. A mechanical property evaluation of graded density Al-Si10-Mg lattice structures manufactured by selective laser melting. Mater. Sci. Eng. A 2016, 670, 264-274. [CrossRef]

18. Vrána, R.; Červinek, O.; Maňas, P.; Koutny, D.; Palousek, D. Dynamic loading of lattice structure made by selective laser melting-numerical model with substitution of geometrical imperfections. Materials 2018, 11, 2129. [CrossRef]

19. Vrana, R.; Koutny, D.; Palousek, D. Impact resistance of different types of lattice structures manufactured by slm. MM Sci. J. 2016, 2016, 1579-1585. [CrossRef]

20. Vrána, R.; Vaverka, O.; Červinek, O.; Pantělejev, L.; Hurník, J.; Koutný, D.; Paloušek, D. Heat treatment of the SLM processed lattice structure made of AlSi10Mg and its effect on the impact energy absorption. In Proceedings of the Euro PM2019 Congress \& Exhibition, Maastricht, The Netherlands, 13-16 October 2019; pp. 1-6, ISBN 978-1-899072-51-4.

21. Kempen, K.; Thijs, L.; Van Humbeeck, J.; Kruth, J.-P. Mechanical properties of AlSi10Mg produced by selective laser melting. Phys. Procedia 2012, 39, 439-446. [CrossRef]

22. Hasan, R.; Mines, R.A.; Shen, E.; Tsopanos, S.; Cantwell, W.; Brooks, W.; Sutcliffe, C. Comparison of the drop weight impact performance of sandwich panels with aluminium honeycomb and titanium alloy micro lattice cores. Appl. Mech. Mater. 2010, 24, 413-418. [CrossRef]

23. Ullah, I.; Brandt, M.; Feih, S. Failure and energy absorption characteristics of advanced 3D truss core structures. Mater. Des. 2016, 92, 937-948. [CrossRef]

24. Veiga, C.; Davim, J.P.; Loureiro, A.J. Properties and applications of titanium alloys: A brief review. Rev. Adv. Mater. Sci. 2012, 32, 133-148.

25. Hwang, J.-S.; Choi, T.-G.; Lee, N.; Lyu, M.-Y.; Gil Lee, D.; Yang, D.-Y. Development of a bendable pyramidal kagome structure and its structural characteristics. Compos. Struct. 2016, 142, 87-95. [CrossRef]

26. Smith, M.; Guan, Z.; Cantwell, W. Finite element modelling of the compressive response of lattice structures manufactured using the selective laser melting technique. Int. J. Mech. Sci. 2013, 67, 28-41. [CrossRef]

27. Gümrük, R.; Mines, R. Compressive behaviour of stainless steel micro-lattice structures. Int. J. Mech. Sci. 2013, 68, 125-139. [CrossRef]

28. Yu, B.; Chien, K.; Abu Samk, K.; Hibbard, G. A mechanism for energy absorption: Sequential micro-kinking in ceramic reinforced aluminum alloy lattices during out-of-plane compression. Mater. Sci. Eng. A 2018, 716, 11-22. [CrossRef]

29. Wu, Y.; Liu, Q.; Fu, J.; Li, Q.; Hui, D. Dynamic crash responses of bio-inspired aluminum honeycomb sandwich structures with CFRP panels. Compos. Part B: Eng. 2017, 121, 122-133. [CrossRef]

30. Wang, J.; Shi, C.; Yang, N.; Sun, H.; Liu, Y.; Song, B. Strength, stiffness, and panel peeling strength of carbon fiber-reinforced composite sandwich structures with aluminum honeycomb cores for vehicle body. Compos. Struct. 2018, 184, 1189-1196. [CrossRef]

31. Plascore CrushLite ${ }^{\mathrm{TM}}$. Available online: https://www.plascore.com/download/datasheets/energy_absorption_ documentation/Plascore_CrushLite-Sheet-Metric.pdf (accessed on 19 August 2020).

32. Fahland, J.; Hoff, C.; Brelin-Fornari, J. Evaluating impact attenuator performance for a formula SAE vehicle. SAE Int. J. Passeng. Cars-Mech. Syst. 2011, 4, 836-847. [CrossRef]

33. Boria, S. Behaviour of an impact attenuator for formula SAE car under dynamic loading. Int. J. Veh. Struct. Syst. 2010, 2. [CrossRef]

34. Vettorello, A.; Campo, G.A.; Goldoni, G.; Giacalone, M. Numerical-experimental correlation of dynamic test of a honeycomb impact attenuator for a formula SAE vehicle. Metals 2020, 10, 652. [CrossRef]

35. Zhang, S.; Chen, W.; Gao, D.; Xiao, L.; Han, L. Experimental study on dynamic compression mechanical properties of aluminum honeycomb structures. Appl. Sci. 2020, 10, 1188. [CrossRef]

36. Chen, Q.; Shi, Q.; Signetti, S.; Sun, F.; Li, Z.; Zhu, F.; He, S.; Pugno, N.M. Plastic collapse of cylindrical shell-plate periodic honeycombs under uniaxial compression: Experimental and numerical analyses. Int. J. Mech. Sci. 2016, 111, 125-133. [CrossRef]

37. Han, B.; Qin, K.; Yu, B.; Wang, B.; Zhang, Q.; Lu, T.J. Honeycomb-corrugation hybrid as a novel sandwich core for significantly enhanced compressive performance. Mater. Des. 2016, 93, 271-282. [CrossRef]

38. Wang, Z.; Liu, J.; Hui, D. Mechanical behaviors of inclined cell honeycomb structure subjected to compression. Compos. Part B: Eng. 2017, 110, 307-314. [CrossRef] 
39. Wang, Z.; Liu, J. Mechanical performance of honeycomb filled with circular CFRP tubes. Compos. Part B Eng. 2018, 135, 232-241. [CrossRef]

40. Balaji, G.; Annamalai, K. Crushing response of square aluminium column filled with carbon fibre tubes and aluminium honeycomb. Thin-Walled Struct. 2018, 132, 667-681. [CrossRef]

41. Segala, D.; Cavallaro, P. Numerical investigation of energy absorption mechanisms in unidirectional composites subjected to dynamic loading events. Comput. Mater. Sci. 2014, 81, 303-312. [CrossRef]

42. Segala, D.B.; Cavallaro, P.V. Energy Absorption Mechanisms in Unidirectional Composites Subjected to Dynamic Loading Events. Available online: https://apps.dtic.mil/sti/citations/ADA564440 (accessed on 19 August 2020).

43. Zhang, Q.; Zhang, J.; Wu, L. Impact and energy absorption of long fiber-reinforced thermoplastic based on two-phase modeling and experiments. Int. J. Impact Eng. 2018, 122, 374-383. [CrossRef]

44. Yu, B.; Deshpande, V.; Fleck, N. Perforation of aluminium alloy-CFRP bilayer plates under quasi-static and impact loading. Int. J. Impact Eng. 2018, 121, 106-118. [CrossRef]

45. HexWebTM. Honeycomb Sandwich Design Technology. Available online: https://www.hexcel.com/user_area/ content_media/raw/Honeycomb_Sandwich_Design_Technology.pdf (accessed on 19 August 2020).

46. Gibson, L.J.; Ashby, M.F. Cellular Solids: Structure and Properties; Cambridge University Press: Cambridge, UK, 1999.

47. PAMG-PA3 5052 Aluminum Honeycomb. Available online: https://www.plascore.com/download/datasheets/ honeycomb_data_sheets/PLA_PAMG_PA3_5052.pdf (accessed on 19 August 2020).

48. HexWebTM. Honeycomb Attributes and Properties. Available online: https://www.hexcel.com/user_area/ content_media/raw/HexWebHoneycombAttributesandProperties.pdf (accessed on 19 August 2020).

49. Ma Quoc, P. Design and Numerical Modeling of Impact Attenuator. Available online: http://hdl.handle.net/ 10084/129693 (accessed on 19 August 2020).

50. Kumar, K.V.; Norfleet, W.T. Issues of Human Acceleration Tolerance after Long-Duration Space Flights. Available online: https://ntrs.nasa.gov/citations/19930020462 (accessed on 19 August 2020).

51. Markopoulos, A.; Hapla, V.; Čermák, M.; Fusek, M. Massively parallel solution of elastoplasticity problems with tens of millions of unknowns using PermonCube and FLLOP packages. Appl. Math. Comput. 2015, 267, 698-710. [CrossRef]

(C) 2020 by the authors. Licensee MDPI, Basel, Switzerland. This article is an open access article distributed under the terms and conditions of the Creative Commons Attribution (CC BY) license (http://creativecommons.org/licenses/by/4.0/). 